\section{DESIGUALDAD EN CHILE}

Por Marcela Perticara* y Mauricio Tejada

*Académica FEN UAH, Ph.D. en Economia, U Texas A\&tM, Estados Unidos.

Cada vez que la Encuesta de Caracterización Socioeconómica adelante podemos analizar cómo ha cambiado la desigualdad de Cada vez que la Encuesta de Caracterización Socioeconómica adelante podemos analizar cómo ha cambiado la desigualdad de
(Encuesta CASEN) entrega sus resultados, se reabre el debate so-
ingresos, en los últimos 10 años, entre los hogares jóvenes cuyo bre los niveles y cambios en la pobreza y desigualdad del ingreso en Chile. Existe siempre mucha expectativa por definir si ha habido una caida (o no) en estos indicadores, tanto que en algunas ocasiones, el debate publico frente a estos resultados se ha tornado ácido con culpas que van desde un sector político a otro. Inclusive, durante la administración pasada, aparecieron acusaciones de manipulación de estadisticas debido a que se había cambiado la metodologia de ajuste de los ingresos.

Esto contrasta con la entrega de este año, en que la CASEN 2015 paso casi desapercibida. Hubo mucho menos propaganda que en periodos pasados pese a que los resultados no eran malos pues mostraron que la pobreza medida por ingresos ha caido de manera sistemática en los ultimos dos años, mientras que los transferencias monetarias del Gobierno) se mantuvieron relativaGráfico 1).

En un contexto como el actual, con un debilitamiento del mercado laboral, resulta interesante evaluar los cambios que pudieran años luego de un par de crisis importantes y de la implementación de las reformas en el sistema de pensiones, además del gran sidio monetario a los hogares más vulnerables de Chile. Pero los indicadores tradicionales de desigualdad de ingresos, como el presentado en el Grafico 1, pueden esconder diferencias de ingresos, ya que las personas en las distintas etapas de su vida enfrentan diferentes condiciones laborales $y$ pueden estar expuestos de forma distinta a programas sociales. Adicionalmente, características como el género y el nivel educativo de las personas también pueden ser fuentes relevantes de heterogeneidad que exacerban el efecto del ciclo de vida. Dado lo anterior, en este artículo tratamos de realizar un ejercicio que nos permita separar los efectos del ciclo de vida sobre las medidas de desigualdad, de tal manera de medir la desigualdad de ingreso al interior de distintos grupos etarios ${ }^{2}$. En el análisis nos concentramos en los hogares y definimos la edad del hogar como la del jefe del mismo. Además, separamos el análisis por género y nivel educativo del
jefe de hogar. Así, por ejemplo, con las medidas presentadas más jefe de hogar es una mujer educada.

El análisis en base a distribuciones condicionales del ingreso por tramo de edad, permite observar que los indicadores de distribución del ingreso convencionales esconden una alta heterogeneidad en la posición relativa de los hogares de acuerdo al ciclo de vida. En particular la inequidad de ingresos es mayor para hogares con jefes hombres de avanzada edad y para hogares de mujeres teridios ha ultima decada, la distribución de ingresos antes de mujer (independientemente de su edad), y para los hombres jóvenes, pero no asi para hogares con jefes hombres mayores de 60 ños, Ahora bien, cuando consideramos subsidios, claramente la politica pública (sin considerar un criterio de costo-beneficio) ha corara de manera importante la distribución del ingreso para todo tipo de hogar. Pareciera que la mejora es mayor para hogares masculinas de maninas más jóvenes y para hog del jefe de hogar notándose un patrón similar, en el sentido que lantes de subsidios), las mejoras son fundamentalmente en hogares con cabezas más jóvenes; después de subsidios, la mejora muy grande para trabajadores de baja calificación (sin ningún (es cos Par a distribución del ingreso en particular, parece hater mejorado los ultimos 10 años a enque existen importantes heterogeneidades de acuerdo al ciclo de vida del hogar. En particular, sin considerar los subsidios monetarios, la inequidad del ingreso es alta actual esquema de protección social compensa en la dirección correcta. Este efecto es particularmente fuerte, como era de eserarse en el segmento de hogares con jefes no calificados. En os hogares con jefes calificados, es claro el efecto del sistema de pensiones, por cuanto la inequidad de salarios crece justamente para el segmento de hogares con jefes en edad de pensionarse. Con todo, sin considerar los costos del sistema de protección, es claro que la politica de focalización de subsidios parece haber sido efectiva en mejorar la distribución de ingresos.
Segun el Banco Integrado de Programas Sociales (http://Www.programassociales.ci/programas), existen al cierre del ano 2015, 22 programas que otorgan mientras que hay 297 programas socides que otorgan algin tipo de benefico

Calculamos medidas de desigualdad condicionales en la edad usando técnicas no paramétricas descritas en Gerfin (1994) "Income Distribution, Income

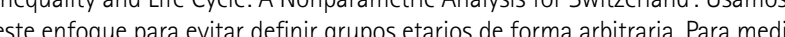
a desigualdad, usamos el indice de Atkinson. Este indice mide la desigualdad de manera diferente al ampliamente usado índice de Gini, ya que permite incorporar en la medida una valoración sobre los ingresos más bajos (o más los hogares de bajos ingresos, emulando asi una sociedad con mayor aversión a dichos ingresos.

coifco 1

Ganancias obtenidas por la industria de AFP en el periodo 2006-2015

(Cifras en millones de US\$ de dicienbre de 2015)

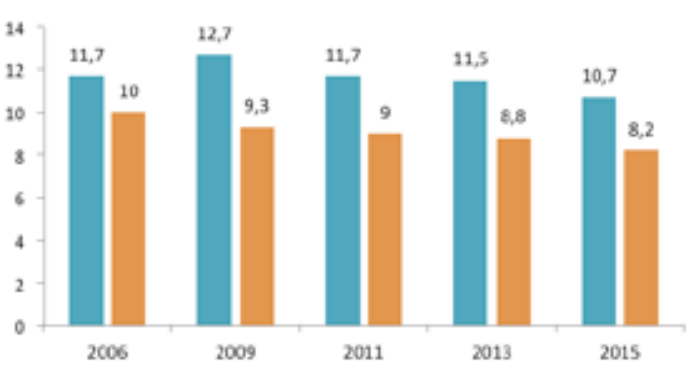

Fuente: Datos extraidos de "Ampliando la mirada sobre
cd", Ministerio de Desarrollo Social, Septiembre 2016.

GRÁFICO 2.

Desigualdad de Ingresos en el Ciclo de Vida İndice de Atkinson

Antes de subsidio

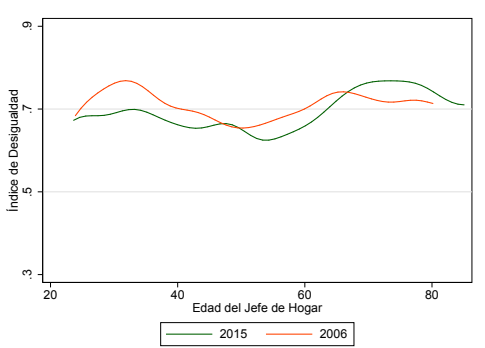

Después de Subsidio

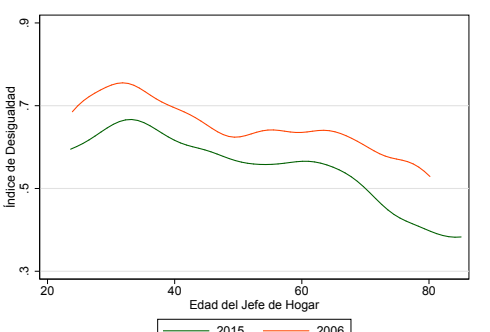

Fuente: Elaboraciön propia en base a CASEN 2006 Y 2015
GRAFCO 3.

Ciclo de Vida. Indice de Atkinson.

sidio - Hombres
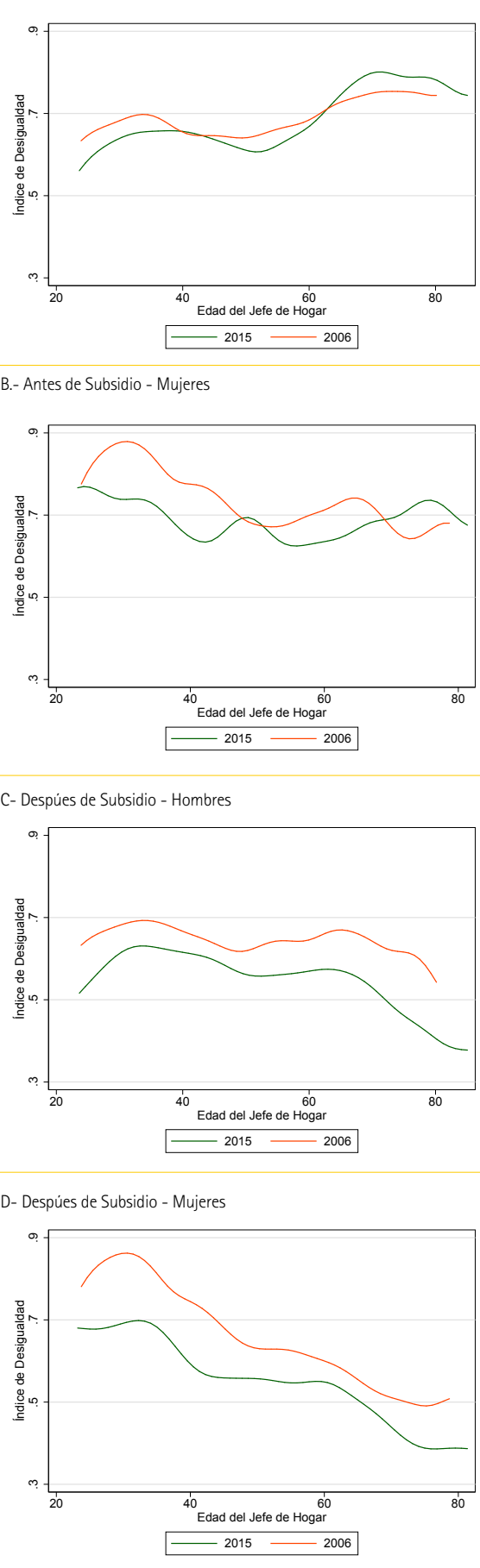

Fuente: Elaboración propia en base a CASEN 2006 Y 2015.

Nota: Cálculos realizados sobre el ingreso per cápita del hogar". haberse producido en la distribución del ingreso en los últimos 10 entramado de programas sociales que otorgan algún tipo de subimportantes asociadas a heterogeneidades inherentes a caracteristicas socio-demograficas de la población, y por tanto podrian dar una idea- erono déc stado de la desigualdad para diferentes fuente de heterogeneidad importante al estudar lin duda una de 60 anos. Como era de esperarse, para los trabajadores calificados la incidencia de los subsidios es casi nula (ver Grafico 3). Para concluir, tanto las estadisticas de pobreza 0 las des.

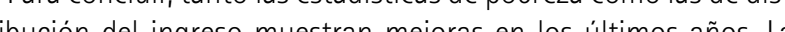
en hogares con jefes mayores de 60 años, aunque ciertamente el

Oe 